\title{
Contribution of selected foods to intakes of energy, fat, saturated fat and non-milk extrinsic sugars
}

\author{
K.L. Barton ${ }^{1}$,W.L. Wrieden ${ }^{2}$, J. Armstrong ${ }^{3}$, A. Sherriff ${ }^{4}$, A.M. Craigie ${ }^{5}$ and A.S. Anderson ${ }^{5}$ \\ ${ }^{1}$ Division of Food and Drink, Abertay University, DUNDEE DDI $1 \mathrm{HG},{ }^{2}$ Human Nutrition Research Centre, Newcastle \\ University, Newcastle upon Tyne NE2 4HH, UK, ${ }^{3}$ School of Health and Life Sciences, Glasgow Caledonian \\ University, Glasgow G4 OBA, ${ }^{4}$ University of Glasgow Dental School, Glasgow G2 $3 \mathrm{JZ}$ and ${ }^{5}$ Centre for Public Health \\ Nutrition Research, University of Dundee, Dundee DD1 9SY
}

Evidence based Scottish Dietary Targets (Revised Dietary Goals since 2013) have been monitored since 2001 ${ }^{(1)}$. The baseline figures used in the setting of these targets were derived mainly from the National Food Surveys of 1989-1991 and were an indication of food and nutrient intake at that time. As national and global food supplies are constantly evolving, it is important to revisit the contribution of different food categories to energy, fat, saturated fat and non-milk extrinsic sugars (NMES) and ensure that the most important foods and drinks are included in the monitoring of overall population intakes.

Household food purchase data from 2001 to 2012, for Scotland, from the UK Living Costs and Food Survey were analysed to estimate the contribution selected food groupings made to intakes of energy, fat, saturated fat and NMES. Adjustments were made for waste ${ }^{(2)}$ and data were analysed using general linear models within the complex samples module of SPSS (SPSS Inc., Chicago, IL, USA) weighting to the Scottish population and taking account of sampling methods. Results are provided for population data (i.e. includes consumers and non-consumers), in descending order by energy contribution. Those contributing more than $5 \%$ to total intake of energy or one of the macronutrients are presented in the table.

\begin{tabular}{|c|c|c|c|c|c|c|c|c|}
\hline \multirow[b]{2}{*}{ Food Grouping } & \multicolumn{2}{|c|}{ Energy $^{1}$} & \multicolumn{2}{|l|}{ Fat $^{1}$} & \multicolumn{2}{|c|}{ Saturated Fat $^{1}$} & \multicolumn{2}{|c|}{ NMES $^{1}$} \\
\hline & $\mathrm{kJ} /$ day & $\%$ & g/day & $\%$ & g/day & $\%$ & g/day & $\%$ \\
\hline Total Confectionery and Sweet Biscuits & 845 & $9 \cdot 8$ & 8.91 & $10 \cdot 3$ & 4.73 & $14 \cdot 0$ & $19 \cdot 17$ & $23 \cdot 4$ \\
\hline Bread and Rolls & 707 & $8 \cdot 2$ & 1.55 & 1.8 & $0 \cdot 35$ & 1.0 & $0 \cdot 00$ & 0.0 \\
\hline Total Processed Red Meat ${ }^{2}$ & 643 & $7 \cdot 4$ & $10 \cdot 66$ & $12 \cdot 3$ & 4.09 & $12 \cdot 1$ & $0 \cdot 12$ & $0 \cdot 1$ \\
\hline Total Milk & 525 & $6 \cdot 1$ & $5 \cdot 56$ & $6 \cdot 4$ & 3.47 & $10 \cdot 3$ & $0 \cdot 27$ & $0 \cdot 3$ \\
\hline Unspecified meal $^{3}$ & 488 & $5 \cdot 6$ & $5 \cdot 91$ & $6 \cdot 8$ & 1.86 & $5 \cdot 5$ & 0.85 & $1 \cdot 0$ \\
\hline Total Fruit and Vegetables & 426 & 4.9 & 0.83 & $1 \cdot 0$ & $0 \cdot 17$ & $0 \cdot 5$ & $6 \cdot 03$ & $7 \cdot 4$ \\
\hline Total Spreading Fats & 402 & $4 \cdot 6$ & $10 \cdot 75$ & $12 \cdot 4$ & $4 \cdot 81$ & $14 \cdot 2$ & $0 \cdot 00$ & $0 \cdot 0$ \\
\hline Sugar Containing Soft Drinks & 329 & $3 \cdot 8$ & $0 \cdot 00$ & $0 \cdot 0$ & 0.00 & $0 \cdot 0$ & $19 \cdot 98$ & $24 \cdot 4$ \\
\hline Cakes, Pastries and Puddings & 264 & $3 \cdot 1$ & $2 \cdot 87$ & $3 \cdot 3$ & $1 \cdot 23$ & $3 \cdot 6$ & $4 \cdot 75$ & $5 \cdot 8$ \\
\hline Total Cheese & 220 & $2 \cdot 5$ & $4 \cdot 38$ & $5 \cdot 1$ & $2 \cdot 78$ & $8 \cdot 2$ & $0 \cdot 00$ & $0 \cdot 0$ \\
\hline Cooking Oil & 207 & $2 \cdot 4$ & 5.59 & $6 \cdot 4$ & 0.64 & 1.9 & $0 \cdot 00$ & $0 \cdot 0$ \\
\hline Sugar & 191 & $2 \cdot 2$ & $0 \cdot 00$ & $0 \cdot 0$ & 0.00 & $0 \cdot 0$ & 11.92 & 14.6 \\
\hline
\end{tabular}

${ }^{1}$ Amount and $\%$ contribution of food grouping to the total intake of nutrient; ${ }^{2}$ May include starch component e.g. pastry/potato/bread; ${ }^{3}$ An unspecified meal is one categorised as a 'meal', 'school meal' or 'meal at work' with no further detail given.

The majority of foods that contribute most energy, fat, saturated fat and NMES are already monitored ${ }^{(1)}$ however there are several additional foods that may warrant monitoring in the future e.g. spreading fats, cheese and cooking oil. The results highlight that confectionery and sweet biscuits, a category that is often only considered to be a high contributor of NMES is also the largest contributor to energy, $2^{\text {nd }}$ largest contributor to saturated fat and the $3^{\text {rd }}$ largest contributor to fat. These results are similar to those found using Kantar WorldPanel purchase data ${ }^{(3)}$. Confectionery and sweet biscuits can only contribute a very small amount to a balanced healthy diet as illustrated by the Eatwell plate. Reducing sugary drinks by two-thirds and halving confectionery and sweet biscuit intake (the top 2 contributors to NMES intake) has the potential to bring population NMES intake below the dietary goal for Scotland ${ }^{(4)}$ (less than $11 \%$ of food energy) and offer a significant reduction in excess energy.

Funded by Food Standards Scotland (FS424018). Data from DEFRA, SNS, ONS and the UK Data Archive.

1. Wrieden WL, Armstrong J, Sherriff A et al. (2013) BJN, 109(10): 1892-1902.

2. Waste and Resource Action Programme (2007) The food we waste. Oxon: WRAP.

3. Food Standards Scotland (2016) Foods and drinks purchased into the home in Scotland using data from Kantar WorldPanel http://www.foodstandards. gov.scot/monitoring-foods-and-drinks-purchased-into-the-home-in-scotland (accessed 29 January 2016)

4. Scottish Government. (2013). "Revised Dietary Goals for Scotland." http://www.gov.scot/Resource/0042/00421385.pdf (accessed 29 January 2016). 